\title{
La lactancia humana como patrimonio vivo: rescatando historia social en la plaza de las Pasiegas de Granada
}

Se presenta una propuesta de investigación en $\mathrm{curso}^{1}$, un proyecto donde se aúnan, y se alían, los estudios de lactancia y los de patrimonio inmaterial (estudios críticos de patrimonio). El objetivo es, pues, doble: (1) rescatar el patrimonio cultural inmaterial (asociado a la plaza de las Pasiegas de Granada) que supuso la práctica de la lactancia por nodrizas, atravesando la historia socio-ciudadana que implicaba la cultura de lactancia (y crianza, por ende) asalariada, para aterrizar (2) en la cultura de lactancia contemporánea denominada lactivismo, que está creando a su vez lo que consideramos nuevas formas de patrimonio vivo.

Ester Massó Guijarro | Departamento de Antropología Social y Cultural de la Universidad de Granada

URL de la contribución <www.iaph.es/revistaph/index.php/revistaph/article/view/4088>

Desde el año 2003, según la UNESCO, el patrimonio inmaterial son todas aquellas "tradiciones o expresiones vivas heredadas de nuestros antepasados y transmitidas a nuestros descendientes, como tradiciones orales, artes del espectáculo, usos sociales, rituales, actos festivos, conocimientos y prácticas relativos a la naturaleza y el universo, o saberes y técnicas tradicionales de fabricación de objetos artesanales". En función de esta definición, encontramos que la lactancia humana y el cúmulo de prácticas y creencias que acarrea, en cualquiera de sus versiones culturales, encarnan al menos varias de estas acepciones; dicho de otro modo, que la lactancia es un patrimonio inmaterial, o vivo, como suele denominarse en antropología, de primer orden, y así queremos vindicarla.

Por otro lado, aterriza o, más bien, parte también esta propuesta de un patrimonio histórico monumental: el de la plaza de las Pasiegas de Granada (Andalucía, España) y, más concretamente, su topónimo. Este popularísimo enclave posee una historia interesante y poco conocida que, a la sazón, le otorga su nombre: la de las nodrizas pasiegas que acudían a "exponerse" para ofrecer sus servicios los domingos en este espacio público (ACALE SÁNCHEZ, 2005; GÓMEZ-MORENO CALERA; CRUZ CABRERA; ANGUITA CANTERO, 2006; BELZA, 19972). No solamente, sin embargo, las oriundas de la Vega del Pas lo hacían, sino que aún viven ancianas granadinas que recuerdan haberse ofrecido como nodrizas los domingos en la plaza de Pasiegas para ayudar económicamente a sus familias. Por otro lado, y por ese mismo motivo histórico, fue esta plaza la escogida por las madres lactantes socias de Mamilactancia, la asociación prolactancia materna de ámbito granadino, para celebrar la tetada pública de la 1. ${ }^{a}$ Fiesta de la Lactancia en Granada en 2004 (GARCÍA, 2004: 13), destinada a la visibilización (orguIlo) y normalización de la lactancia en nuestra sociedad. Hallamos así, pues, enlazadas dos formas de patrimonio, la más monumental, arquitectónica y urbana que es esta plaza, con la más intangible que tiene que ver con la historia y presente de las mujeres, de algo tan viejo, y a la vez tan nuevo en su interpretación (MASSÓ GUIJARRO, 2017a), como es la lactancia humana. Este proyecto nace confrontando aquellas dos imágenes ciudadanas (siguiendo estudios sobre los espacios íntimos y ciudadanos vinculados al género de Smyth -2008-, entre otros) profundamente vinculadas pero, a la vez, distanciadas por el tiempo y las representaciones colectivas. En este sentido, resulta de gran interés estudiar en profundidad desde la antropología esta parte de la historia, con un enfoque crucial de historia de las mujeres y de género, de un lado, y patrimonialista, de otro, para visibilizar y hacer llegar a la ciudadanía este conocimiento, resignificándolo además con la vivencia actual en torno a la lactancia. 


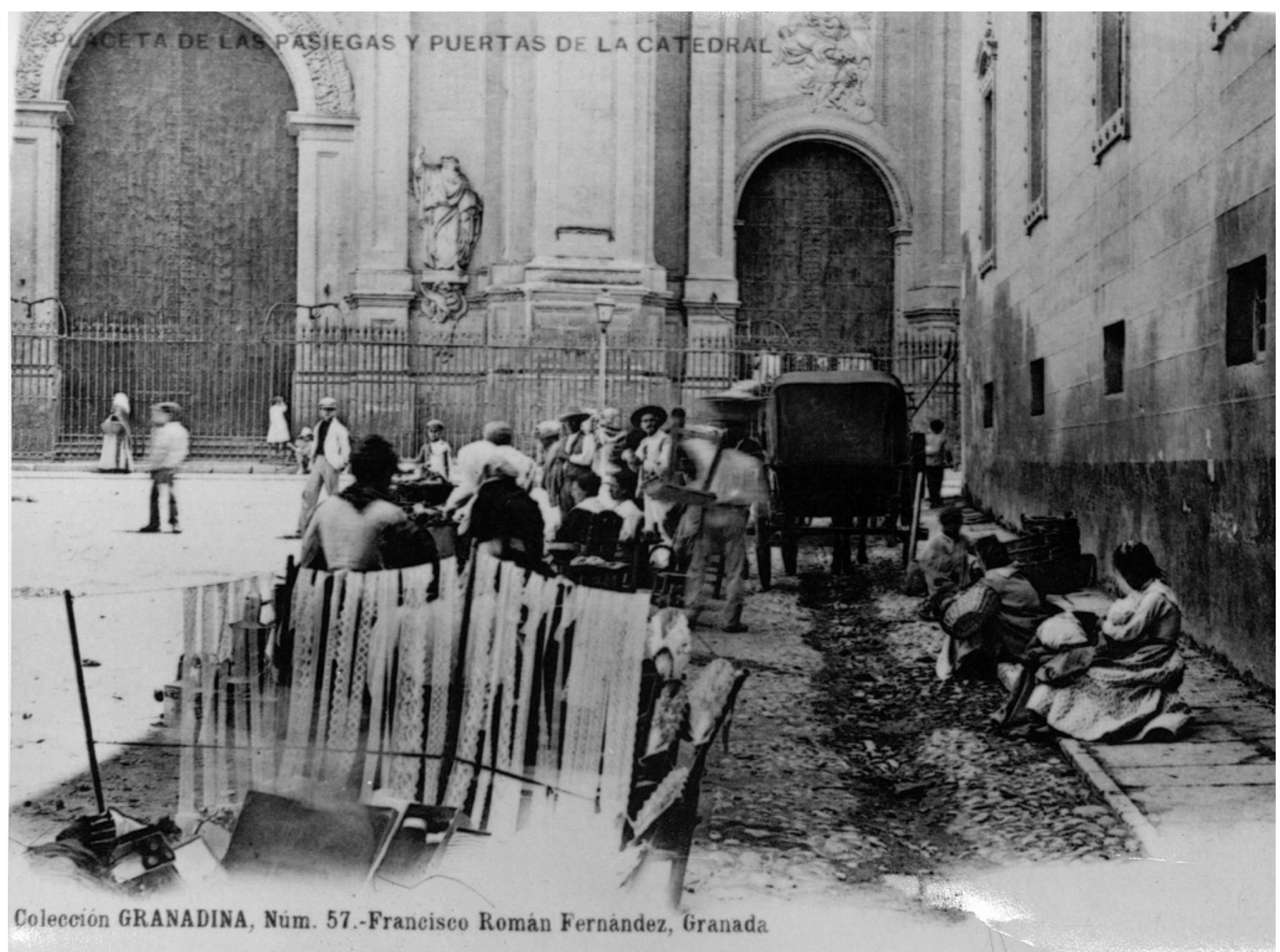

Placeta de las Pasiegas y puertas de la catedral, entre 1890 y 1899 | foto @ Ayuntamiento de Granada. Archivo Histórico Municipal de Granada (Francisco Román Fernández)
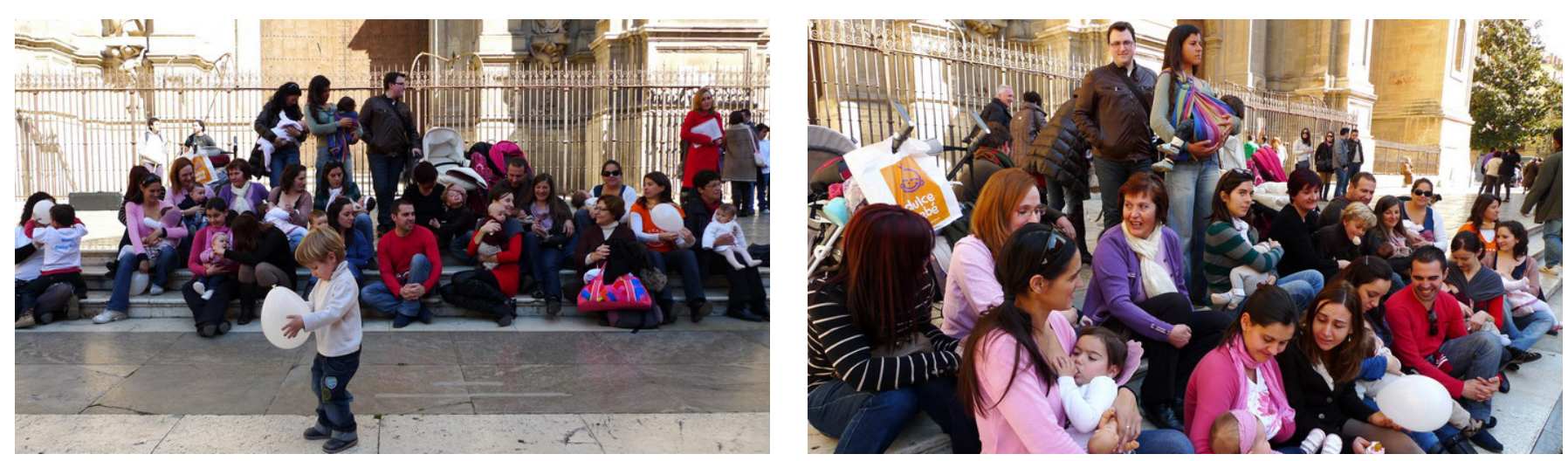

Tetada pública en Pasiegas por Mamilactancia | fotos Pepa Ponce 




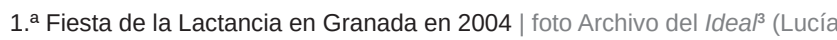
Rivas)

Las imágenes que ilustran este texto son motivo para una revisita a un patrimonio cultural (material, monumenta ${ }^{4}$ ) granadino crucial, como es la plaza de Pasiegas, como pretexto para estudiar un patrimonio vivo, desde la memoria oral pasada hasta la más contemporánea, como es una práctica relacional de crianza crucial, a saber, la lactancia materna. Buscamos, además, contrastar ambas memorias y ambas experiencias sobre la lactancia, culturalmente marcadas por muy diferentes influencias y que generan, en realidad, dos culturas de lactancia distintas -opuestas incluso en algunos puntos, como estamos analizando-: la cultura de lactancia asalariada y la cultura de lactancia contemporánea que hemos dado en llamar "lactivismo" (MASSÓ GUIJARRO, 2015).

Así nos hallamos con dos patrimonios inmateriales-vivos, arraigados en la memoria oral y en el presente cotidiano de muchas madres hoy, que se diferencian y se vinculan a un tiempo: de un lado, la historia cultural, viva y patrimonial de la plaza, tanto la más antigua como la que aún pueden narrar las ancianas entonces madres lactantes; de otro lado, la realidad contemporánea de grupos de madres que experimentan y fomentan la lactancia de un modo ciertamente distinto, con un cariz público que asume otros significados.

Desde la perspectiva del patrimonio como construcción social y del espacio urbano (GONZÁLEZ ALCANTUD, 2012; PRATS, 2004; CHOAY, 2009; KIRSHENBLATT-
GIMBLETT, 2004; DELGADO, 2006), consideramos que tanto las nodrizas (pasiegas o granadinas) de entonces, como las madres lactantes (lactivistas) de hoy, han producido y producen formas de patrimonio inmaterial ligados a su práctica lactante, que en el caso de la plaza de las Pasiegas se vincula inextricablemente, además, a un patrimonio cultural y artístico emblemático.

Finalmente, si el concepto de patrimonio, sobre todo en su matiz cultural, inmaterial u holístico, está realmente experimentando un proceso de descolonización y subalternización (MASSÓ GUIJARRO, 2016), entonces la lactancia materna, como práctica humana y en su intrínseca variabilidad, constituye un acervo patrimonialista de primer orden.

\section{NOTAS}

1. El presente texto constituye una síntesis divulgativa del artículo MASSÓ GUIJARRO, 2017b (ver bibliografía). Agradezco especialmente a José Luis Navarrete Casas, dinamizador del interesante espacio virtual Granada Antigua en Facebook y gran conocedor de la historia local, su amable colaboración en la búsqueda de fuentes sobre la plaza de las Pasiegas. Asimismo, reconozco expresamente a Cándida Cabrera, presidenta durante largo tiempo de la asociación Mamilactancia, su inestimable colaboración tanto a este respecto como en muchos otros de la presente investigación.

\section{Cf. también ARNÁlZ (2008), FRAILE GIL (2000) y HERNÁIZ Y SÁIZ (2010).}

3. Agradezco a Amanda Martínez, del Ideal, así como a la propia autora de la foto, Lucía Rivas, la amable gestión al respecto de la imagen y la cesión de la misma para ser reproducida aquí. Si bien la imagen resulta significativa en sí misma y es relativa a la primera fiesta de la lactancia, en concreto fue tomada en la plaza de Bibrambla, aledaña a la de las Pasiegas (aunque este fue el lugar escogido para la celebración, carece de bancos, de manera que durante la tetada las madres se sintieron más cómodas en este espacio alternativo que comunica directamente con el primer lugar; por este mismo motivo, 
las sucesivas celebraciones de los años siguientes se trasladaron siempre al Parque García Lorca, pensando en el mayor bienestar de madres y criaturas lactantes, y a pesar de la pérdida de "fuerza simbólica", por así decir, del topónimo).

4. Cf. MASSÓ GUIJARRO (2016) para una discusión sobre la dicotomía "material-inmaterial" aplicada al patrimonio.

\section{BIBLIOGRAFÍA}

- ACALE SÁNCHEZ, F. (2005) Plazas y paseos de Granada: de la remodelación cristiana de los espacios musulmanes a los proyectos de jardines en el ochocientos. Granada: Universidad de Granada, 2005

- ARNAIZ, M. (2008) La leche materna de las nodrizas crió a reyes, aristócratas y burgueses. El Diario Montañés [en línea], 12-10-2008, <http://www.eldiariomontanes. es/20081012/sociedad/domingo/leche-materna-nodrizascantabras-20081012.html> [Consulta: 21/04/2017]

- BELZA, J. (1997) Las calles de Granada. Granada: Comares, 1997

- CHOAY, F. (2009) Le patrimoine en question. Anthologie pour un combat. París: Editions Du Seuil, 2009

- DELGADO, M. (2006) Sobre antropología, patrimonio y espacio público. Revista Austral de Ciencias Sociales, n. ${ }^{\circ} 10$, 2006, pp. 49-66

- FRAILE GIL, J. M. (2000) Amas de cría. Valladolid: Fundación Joaquín Díaz, 2000

- GARCíA, R. (2004) Un grupo de madres da el pecho a sus bebés en la calle para reivindicar la lactancia materna. Ideal, 16 octubre 2004 , p. 13

- GÓMEZ-MORENO CALERA, J. M.; CRUZ CABRERA, J. P.; ANGUITA CANTERO, R. (2006) Granada en tus manos. Centro histórico I. Sevilla: Corporación de Medios de Andalucía, 2006

- GONZÁleZ ALCANTUD, J. A. (2012) El malestar en la cultura patrimonial. La otra memoria global. Madrid: Anthropos, 2012

- HERNÁlZ GÓMEZ, L.; SAIZ PUENTE, M. S. (2010) La vida láctea: historia del amamantamiento. Madrid: Foren21 Formación, 2010

- MASSÓ GUIJARRO, E. (2015) Lactivismo contemporáneo en España: ¿una nueva marea sociopolítica? Journal of Spanish Cultural Studies, n. ${ }^{\circ} 16,2016$, pp. 1-21

- MASSÓ GUIJARRO, E. (2016) ¿Giro decolonial en el patrimonio? La Liberation Heritage Route como alternativa poscolonial de activación patrimonial. Pensamiento. Revista de Investigación e Información Filosófica [en línea], vol. 72, 2016, pp. $1277-1295<$ http://revistas.upcomillas.es/index.php/ pensamiento/article/view/7713/7530> [Consulta: 12/12/2017]

- MASSÓ GUIJARRO, E. (2017a) (dir.) Mamar: mythos y lógos sobre lactancia humana. Dilemata, Revista Internacional de Éticas Aplicadas [en línea], n. ${ }^{\circ}$ 25, 2017, pp. 1-12 <http://www.dilemata.net/revista/index.php/dilemata/article/ view/412000128> [Consulta: 12/12/2017]

- MASSÓ GUIJARRO, E. (2017b) La plaza de las Pasiegas en Granada: lactancia y patrimonio, una propuesta de investigación. Dilemata, Revista Internacional de Éticas Aplicadas [en línea], n. ${ }^{\circ} 25,2017$, pp. 85-94 <http://www.dilemata.net/ revista/index.php/dilemata/article/view/412000134> [Consulta: $12 / 12 / 2017$

- SMYTH, L. (2008) Gendered Spaces and Intimate Citizenship: The Case of Breastfeeding. European Journal of Women's Studies, n. ${ }^{\circ} 15,2008$, pp. 83-99 